\title{
Understanding why women are under-represented in Science, Technology, Engineering and Mathematics (STEM) within Higher Education: a regional case study
}

\author{
Michael Christie ${ }^{\mathrm{a} *}$, Maureen 0’Neilla, Kerry Ruttera, Graham Young ${ }^{\mathrm{a}}$, Angeline Medland ${ }^{\mathrm{a}}$ \\ aUniversidade de Sunshine Coast, Queensland, Austrália \\ *mchristi@usc.edu.au
}

\begin{abstract}
Participation rates of women in Science, Technology, Engineering and Mathematics (STEM) is comparatively low and their attrition rates high. An obvious solution is to attract more women to study such subjects. In 2016 the authors undertook research to find out why so few women enrolled in STEM subjects and investigate ways of increasing their recruitment and retention in this area. The informants in our study were enrolled in a tertiary preparation course as well as nursing and education programs. A critique of the literature was used to develop a survey that informed focus group and interview schedules which were used in collecting data. Our study found that many of the factors that hindered women from applying for STEM courses twenty years ago still apply today and recommends actions that can help increase recruitment of women into STEM and assist their retention and graduation in those areas of tertiary education.
\end{abstract}

Keywords

Diversity in STEM. Sustainability in STEM. Gender Balance.

How to cite this article: Christie, M., O’Neill, M., Rutter, K., Young, G., \& Medland, A. (2017). Understanding why women are under-represented in Science, Technology, Engineering and Mathematics (STEM) within Higher Education: a regional case study. Production, 27(spe), e20162205. http://dx.doi.org/10.1590/0103-6513.220516

\section{Introduction}

Twenty years ago Hanson (1996) argued that although female students have demonstrated interest and aptitude in Science, Technology, Engineering and Mathematics (STEM), they were under represented in STEM subjects at both secondary and tertiary levels of education. Female students who graduated from university in these subjects were also found to be more poorly paid and did not do as well in terms of their career as did their male counterparts. Eisenhart \& Finkel (1998) conducted an extensive review of US women in science and found that females tended to have lower status and more marginal positions in engineering and science. They argued that women who enrol in science subjects and start science careers are attracted to jobs that involve social, political or environmental areas of employment (Eisenhart \& Finkel, 1998, p. 204). They also suggested that women tend to be more comfortable in these areas because the work environment is friendlier even though the pay and status attached to them are lower. These findings were backed up by other research studies on the gender gap in STEM subjects in the United States. The National Centre for Education Statistics (NCES) concluded that "[...] girls are less likely than boys to aspire to careers in science and engineering" (National Centre for Education Statistics, 1997, p. 27). The NCES noted that the maths and science proficiencies of boys and girls are similar to the age of nine but then a gap appears at age thirteen (National Centre for Education Statistics, 1997, p. 1). By seventeen the gender gap in maths and science narrows slightly but because of the fairly radical change in the attitudes of boys and girls after grade 8 (age thirteen) the gap is never bridged (National Centre for Education Statistics, 1997, p. 17). The 1997 report listed many factors associated with this persistent gap between boys and girls in terms of STEM subjects. They included location, particularly remote locations, varying 
education systems, such as Catholic, independent and state, and low social-economic background (SES). The NCES cited enrolment statistics for tertiary intake of men versus women which indicated that "[...] men outnumber women in mathematics, statistics, sciences (particularly physics), engineering, manufacturing, construction and computing, while women outnumber men in the study of health, welfare, education, humanities, arts, agriculture, life sciences, services, social sciences, business and law" (National Centre for Education Statistics, 1997, p. 27). One might imagine that in the two decades after this report was published a great deal would change, especially as there was already a perceptible fall in enrolments in STEM subjects at the university level in the US, the UK, Australia and other developed countries. These falls in student enrolments was particularly prevalent in Engineering.

\section{The current state of the gender gap in STEM}

Nearly two decades after its 1997 report the National Centre for Education Statistics (2013) made it clear that the US gender gap in STEM subjects at the university level remains. The same can be said for other developed countries. When one compares US data from NCES between 1997 and 2013 with data from Australia for the same timeframe, the common theme that emerges is that women are under-represented in STEM fields throughout their education and career (National Centre for Education Statistics, 1997, 2013; Australian Council of Learned Academies, 2013, p. 134). One note of optimism is that there has been some gradual improvement in some of the most under representated STEM subjects. According to Freeman $(2004$, p. 30) in the early 1970s in the US, females accounted for less than 1\% of undergraduate degrees conferred in engineering. Data from Australian Council of Learned Academies (2013) showed that the same figure was true of Australian female graduates in engineering degrees in the early 1970s. Two decades later, in 1996, the number of Australian female engineering graduates was 5.2\% (Australian Bureau of Statistics, 2001). Roberts \& Arye (2002) noted that Australia trailed both the UK and the US in the percentage of women engineers that they graduated. In 1996, in the UK, women represented 7 per cent of professional engineers and technologists (Glover, 2002). The US National Science Foundation found that 9\% of graduate engineers were women in 1998, while Lal et al. (1999) found that in 1999 women held 10\% of professional engineering jobs in the US. Australian Council of Learned Academies (2013) reports that in Australia, women's participation in STEM has improved over the two decades since 1993, but that there is a case to be made for re-invigorating the agenda on women in STEM (Australian Council of Learned Academies, 2013, p. 153). Today that number of female engineering graduates has risen to 20\% in Australia which is the same figure for the US a decade earlier (Freeman, 2004; National Science Foundation, 2004). In Australia national estimates suggest that gender disparities, specifically in engineering, are largely driven by "[...] inadequate enrolment (not inadequate retention) of women" (Australian Council of Learned Academies, 2013, p. 211).

Inadequate enrolments are still the main reason for gender disparities in US engineering universities. A longitudinal study conducted by National Science Board (2010) that used primary sources from the American Society for Engineering Education (ASEE), the Engineering Workforce Commission (EWC), and Engineering Trends found that the under-representation of women in Engineering Education for the academic years 1999-2000 through 2004-2005 was predominantly due to low enrolments in Mechanical, Computer, and Electrical Engineering programs. The female enrolment in those subjects was between $12 \%$ and $14 \%$ compared with the national average for female enrolment in engineering courses, which was $20 \%$ to $22 \%$. The disciplines where women were, on average, over-represented, when compared to the national average, included Bio-engineering (38\%), Environmental Science (37\%), Chemical Engineering (35\%), Industrial, Management and Manufacturing, and Architecture (29\% each).

A key question is whether retention in engineering is lower among women than men. The above study shows that female students comprised 20\% of national engineering enrolments between 1999 and 2004 and during the same time women represented 22\% of degree recipients (National Science Board, 2010). This indicates that issues of female under representation, especially in the field of engineering, is not due to drop-out rates of female engineering students but rather low enrolment rates. The earlier Australian study by Roberts \& Arye (2002) found that this is also true of Australian Engineering Education. They point out that there is little or no difference in retention rates between men and women in engineering and that the proportion of women and men who begin working as engineers after graduation is almost equal - 85\% for women compared with $89 \%$ for men. The number who subsequently left these jobs is also very similar. Women engineers in the 30-39 age bracket who stopped working as engineers made up 45\% of the total. Another 17\% left the job after they turned 40 years of age or more. The percentage of males who stopped working in the 20-29 age bracket was 40\%. Those who left after 30 years of age made up 20\% or less of the total (Roberts \& Arye, 2002, p. 7). 


\section{Gender equality}

In a number of OCED countries measures have been implemented to ensure a more equitable percentage of women in STEM disciplines such as engineering (Organisation for Economic Co-operation and Development, 2014, p. 6). One measure that universities worldwide are attempting to institute, involves scholarships and fellowships specifically targeted at female students and researchers in areas such as engineering. Another scheme introduced in 2009 by Ghent University, Belgium, was to provide young female PhD researchers with mentors. Increasing the visibility of female role models in engineering and other STEM subjects is another way to highlight the presence, excellence and outstanding contributions of women in STEM fields. The Gender Equality Observatory, for example, publishes an annual calendar that depicts such women and their achievements in various scientific fields. In 2010 the calendar focussed on women in the field of Chemistry. In Australia the government, via its Department of Education Science and Training (DEST), has introduced a Maths and Science partnerships Program (AMSPP) project worth $\$ 16.4$ million available over three years to enable universities across Australia to deliver innovative math and science projects to increase participation of both males and females in STEM. The main purpose is to improve student engagement in maths and science courses through innovative partnerships between universities, schools, and other relevant organisations. Despite these initiatives falling interest in STEM subjects generally, and gender inequality in Engineering and Science Education in particular, persists. Strachan et al. (2008, p. 323) argue that "[...] gender equity is yet to be achieved with significant remaining barriers in academic and senior positions". Reports from the Organisation for Economic Co-operation and Development (2014) and from (Department of Education Science and Training, 2006, 2015) make the same point.

Australian universities tend to have a strong record on positive gender policies but inequitable practices are hard to change. In fact universities continue to allow unequal outcomes for men and women in terms of pay and status (Probert, 2005, p. 50). Female academics are concentrated in lower job classifications, receive less than average pay and are more often employed in casual positions (Equal Opportunity of Women in the Workplace Agency, 2005, p. 30-35). Department of Education Science and Training $(2006,2015)$ confirmed this lack of progress in terms of gender equity in two reports written a decade apart, showing that women in Australian universities are under-represented in full- time and on-going positions and in senior roles. Similarly in the UK two reports published in 2013 and 2015 showed that although approximately 55\% of all UK first-degree students were female this percentage does not subsequently translate in terms of those graduates who eventually become academics in that discipline. Biosciences, for example, has over 60\% female students but only 15\% of their professors are women.

Four years ago The House of Lords Science and Technology Committee (2012) completed an inquiry into STEM in higher education that identified a need for increased numbers of employable, skilled STEM graduates as a matter of urgency for the economic health of the UK. This report highlights the need to increase the number of students who might go on to take STEM related subjects at university in general but also stresses that a low female uptake in stem subjects in compulsory schooling will only compound the current problem of gender inequality in these subjects at the university level. The need to increase female numbers is crucial in areas such as the Built Environment (Fielden \& Davidson, 2010), Engineering (Wallace \& Sheldon, 2014), Mathematics (Boaler \& Mckenna, 2011) and Physics (McCullough, 2004). One way forward is to find more creative ways to recruit and teach women in STEM subjects such as engineering.

Another group that does not usually make up a significant proportion of students in Engineering Education and other STEM subjects at university are students with low socio-economic status (SES) backgrounds. Thomas (2014) has argued that particular strategies can be adopted by regional universities to recruit, teach and retain such students. He argues that students from this type of background encounter greater challenges and barriers in adapting to university and in particular to those subjects that are deemed hard, such as mathematics and engineering. He points out that this group has fewer 'encouragers' and suggests that the pathways and pedagogies that universities adopt need to be modified for such students. From what we have presented above we feel that the same can be said for young women who may aspire to undertake an engineering or mathematics degree but all too often lack encouragement to do so. In his study Thomas interviewed 19 teachers and leaders form 12 regional Australian universities and concluded that the strategies that could be advantageously employed to retain students from low SES background could include active learning pedagogies. In our own case study we focused on why male students from low SES background do not enrol in university and also on why women who were enrolled in more traditional female courses, such as nursing and education, did not choose STEM subjects. Given limitations of space and the theme of this article we restrict our report to the latter topic. 


\section{Methodology}

In 2015 a group three researchers and two administrators received funding from the Australian government's Higher Education Participation and Partnerships Program (HEPPP) which aims to ensure that prospective students from low Socio-Economic Status (SES) backgrounds, who have the ability to study at university, get the opportunity to do so. HEPP provides funding via a National Priorities Pool and the authors of this paper were successful in receiving a grant to undertake a project entitled 'Removing Barriers to Engagement by Tertiary Students'. As mentioned above there were two parts to the project. The first part was aimed overcoming the under-representation within Higher Education of non-indigenous young males (aged 20 to 34 years). The second part, which is the focus of this paper, aimed at researching ways to widen the aspirations of non-indigenous young females (same age grouping and location) so that they consider studying degree programs in areas outside the commonly chosen ones of nursing and teaching, for example, STEM related subjects such as engineering. Two of the researchers in the project also teach in the Tertiary Preparation Pathway or TPP program at the research site.

Our project was designed as a piece of educational action research consisting of two cycles that each involve a spiral process of planning, acting and evaluating. Cycle one includes the analytical, critical literature review that led to the development of a survey that was administered and which helped inform the questions used in the focus groups and structured interview that comprise part of cycle one. Cycle two consisted of practical interventions to help improve the enrolment of women in STEM subjects at the rural campus that was the focus of the research. Action research is grounded in the philosophy of John Dewey (1916), that adheres to the action research principles of Kurt Lewin (1946), and follows the main methodological recommendations of Carr \& Kemmis (1986). Kemmis \& McTaggart (1988) subsequently developed a model of participatory action research which is the version of action research that we have adopted. The intention of all action research is to make changes for the better. In this sense it is both partisan and transformative (Mezirow, 1991). Since 1988 action research has become more and more relevant to educational improvement. Jean McNiff, together with her colleague Jack Whitehead, has been an important author in assisting school teachers and academics with practical and easily accessible booklets and books on educational action research which she updates in new editions (Whitehead \& McNiff, 2006; McNiff, 2013).

\section{Data collection, analysis and results}

Participants were recruited via announcements that were added to an events page on an official university Facebook site as well as by word of mouth.

\subsection{The survey}

Eleven female students agreed to participate and formed two focus groups of five people. The remaining person participated in a structured interview that used the same questions as the focus groups and the results of that interview are interwoven into the data analysis. The groups met during March and April 2016 and the interview was conducted at the end of the process. From the survey we were able to ascertain that there were three 21 year old participants, four aged 25, 27, and 29, two aged 30 and two aged 34. Eight had gone to government schools and three to private colleges. Their intended or current degrees were education, nursing, and social work but five were completing their TPP studies as part of their first year. Qualitative questions in the survey elicited information on following topics: 1) self-perception of school attainment; 2) opinions on continuous assessment; 3 ) beliefs and feelings about mathematics; and, 4) friends that went on to do tertiary studies.

In terms of self-perception of school attainment participants responses varied. One said she had a positive self image at school and was very organised having worked as an admin assistant after school (S1); another said her tried as well as she could at school and that she "had great peers and engaging teachers" (S2); a third respondent said she was "Average...as 1 had a lack of interest" (S3) while a fourth said her perception of her schooling was "Excellent! I was interested in subjects and had family support" (S4). Others felt that they had done "Pretty well" (S5); "Average- because I got an average OP score" (S6); "Ok - because l got my certificate" (S7); “Not great- 1 wasn't committed” (S8); “Some subjects - good. Maths - not so good. Algebra and equations were problematic" (S9); "Average- I did well in subjects l enjoyed and with teachers who were engaging” (S10); and the final informant said "I struggled with Maths at school and this really went against me in my achieving whilst at schoor' (S11). In our summary of the data we concluded that the group varied from being 'ok' and 'average', to doing 'excellently' due to family support (this latter comment was from S4 a mature-aged student 
who had completed previous studies and was not the first in her family to undertake tertiary studies). Private education was an advantage (S2 and S10) and mathematics was definitely problematic (S9 and S11).

The second question related to the advantages and disadvantages of continuous and varied assessment, including group work assessment. This question was included because earlier research by Christie \& Nordlund (2006) found that continuous assessment was perceived to be beneficial to female students. The responses included the following comments: "I prefer small group work projects" (S1); "Consistent assessment tasks are OK and challenging. Individual is preferred" (S4); "I like group work and find it more fun and appealing to do assessments in a group" (S5); "Yes. I would feel more confident with a number of people to bounce ideas off' (S8); "Yes- I think working in groups would be better for me" (S9); "I prefer constant assessment tasks. 1 feel I can gauge how l'm going with feedback from regular assessment" (S10). "Group work is a good test of my skills and knowledge as I prefer working solo" (S6). Others were less positive: "I would not prefer to solve problems in groups as I find a lot of people don't participate in groups effectively"(S7); "I prefer individual assessments as it is sometimes difficulty to rely on peers" (S2); "Yes \& no - l enjoy working by myself but also benefit from group work/discussions" (S3). We concluded that five students definitely prefer group work, two were unsure and three students prefer only individual assessments as they do not want to rely, as S9 said, "on peers but preferred to get feedback from regular assessment". The responses backed up the findings of our earlier research.

The next question asked respondents about their attitude to Mathematics. They responded as follows: "I enjoyed maths" (S1); "Didn't love it, but didn't hate it" (S2); "I very much disliked maths" (S3); "Not much" (S4); "I can do it - but really don't like it" (S5); "I was good at Maths - top of the class" (S6); "Hate it" (S7); "I struggled" (S8); "I like Maths - excluding Algebra and equations" (S9); "I felt I was poor at Maths, didn't enjoy it" (S10); "I struggled at Maths - really dislike it" (S11). In summary we concluded that three participants liked maths, three were impartial and five students definitely disliked it due to their struggling with maths concepts.

Our third question probed whether or not the respondents had friends that went on to do tertiary studies. Three informants (S1, S3 and S4) said they did not have such friends and S11 also responded negatively saying "No - none of my friends went to university". The others responded as follows: "Most of my school friends went onto university from my private schoor" (S2); "Yes- 5 of them" (S5); " 4 of my friends went on to university" (S6); "Yes - 10 to 15 of them" (S7); "Yes - 2 or 3 of them" (S8); "Yes - 6 of them" (S9); "Yes - 3 of them" (S10). We concluded that most of the participants had school peers that went on to university studies.

\subsection{Themes from the focus groups and the interview}

The duration of the two focus groups and the structured interview was between 45 minutes and one hour. Each focus group was co-ordinated by a facilitator and a scribe who recorded field notes and observations. The focus groups and interview were recorded and transcribed verbatim. A standard script was read out by the facilitator and all participants were asked to sign a consent form in accordance with the ethics clearance for this project. The topics for the focus groups and interview were informed by the survey but kept open ended and the conversation focussed on why the women had chosen their particular program rather than entering a STEM program. Data were analysed using a thematic coding approach with responses categorised according to evolving themes using an inductive approach and thematic examination. Transcripts were imported and coded in NVivo 11. Using word queries, themes were recognised and identified. There were ten themes that emerged from our analysis of the data. They were as follows:

Theme 1: Misconceptions about Science, was alluded to by five of the informants who made the following points: "Since starting my second degree 1 realise 1 was under a lot of misconceptions - 1 just have the base knowledge to do science, so I did psychology" (S1); "Just didn't realise that l could have been a marine scientist or that 1 could go to space" (S2); "I loved collecting the data - like when 1 was in biology - but just had no knowledge how to analysis or synthesis all of it" (S4); "I know it's about being in lab and Bunsen burners and stuff like that - just couldn't imagine me being inside on a computer - l'm too much of an outdoor type" (S3);

I did science, 1 think that we all did science but I didn't feel like 1 was interested in it when 1 was younger. But then as it got more difficult in coming up to grade 11 and 121 didn't enjoy it because I didn't understand it. I didn't feel a connection with the teacher and that made me hate it to be honest. l'm enjoying it now though, revisiting it at university with a different mind frame and different teachers (S10).

Theme 2: Self Doubt, was expressed by three participants who mentioned that they did not feel that they were not smart enough to undertake STEM. S6 said she did not

[...] feel smart enough to do something like that. At school they give you an Overall Position (OP) rank when you graduate and most of the time to get into STEM you need a really high OP rank. So it really limits your chance of 
actually getting into those subjects and then you're like, hang on, am I smart enough to do this because you've just had all your hopes and dreams crushed by a number? STEM does involve maths - intensive maths with all these complicated equations and all these formulas that you have to remember.

Another participant said: "STEM looks so technical and it looks like you would just need a tremendous amount of skill. You'd have to be very good at maths and sciences and that's always something that you would have to be very bright and done very well at school that's what 1 would think. 1 guess 1 do struggle with a fair bit of self-doubt" (S10). The third participant admitted: "Too much study and not intelligent enough - l'm not a whizz kid. Definitely need support to do math” (S4).

Theme 3: Separation Anxiety, included concerns about moving overseas or to another country to study. One participant spoke of their anxiety about leaving their family: "I personally couldn't because 1 wouldn't be able to leave my family here. So no, living in another country doesn't interest me at all' (S9).

Theme 4: Doubts about where a STEM career would lead, was commented on by four participants who spoke of being unsure about going into STEM careers as they did not know where it would take them:

I was sort of thinking in high school you're never really told where things - where they go. So if you did have a slight interest in something what the end product could be from that, so maybe more careers stuff - advice in high school. I mean 1 know there is some careers but I definitely wasn't exposed to knowing more. So if I maybe had that basic understanding when 1 was ready for university 1 might have picked something else possibly (S8).

Another commented:

When 1 was in school, science was just dissecting a frog to me and it was - l saw no point in it or where it could lead to and then beginning nursing and realising there's a bit of science behind that, was horrible. Because honestly when 1 was in science in high school my big thing was lighting the Bunsen burner and scaring the crap out of the teacher, whereas now it's like I wish l'd paid attention to the periodic table and how an atom works and all that. $I$ got to know where the "road is going" so that is why I didn't consider STEM - I honestly couldn't see myself in any of those roles like making the prosthetic legs (S7).

Participant S10 said:

I feel like we weren't exposed to anything or helped in any sort of direction - we were told if we didn't get a good OP that you would go nowhere and you would be down at Centre-Link. So now I feel like there's so much pressure on young people when actually we can just go get a ranking, go and do TPP, those sort of things and learn our chemistry and our bioscience and things that we thought we wouldn't be able to do (S10).

Another response was: "Probably if 1 had someone already in my family doing this I maybe would have considered it' (S4).

Theme 5: Lack of caring and an absence of a child friendly ethos, concerned the perceived nature of a career in STEM. Four participants mentioned the latter point:

1 would not consider any sort of a career path or study towards a career path that wasn't child friendly because 1 think life is short and time to me is more important than anything else. Children aren't young for very long so my time with my child is what matters the most. Teaching allows me to go home at three and have the same holidays. Not having to worrying about putting your child in day care over school holidays is something that really appeals to me. I wouldn't ever rule anything out but I think that the whole thing with the with the child friendly hours is what really limits females to certain career choices. I would like to do teaching because it works in with family commitments as well as I think it's a fairly well paid position and l like children I suppose (S9).

Another said: "I'm quite passionate and care too much to get into something that doesn't really spark my interest - honestly it would have to be the money even though that sounds very vain" (S7). One, whose mother and aunt are nurses, said enrolling in nursing

[...] sort of runs in the family. My dad said I can't do anything with accounting or business, which I wanted to do, so $I$ went to nursing. With nursing you know that when you have a kid people will be supportive of that, like it's caring, like people care, so you're not going to be forced into quitting your job when you're pregnant or being discriminated against because you're pregnant or you have a family (S6).

Another, who is enrolled in teaching said: "I had some experience in a school which got me started wanting to be a teacher because 1 suppose it is caring about people. I want to work in special education where kids would need people who are interested and would be passionate to be there, so it's a caring role" (S8). 
Theme 6: STEM jobs are male dominated, was endorsed by four participants. One felt that:

As a child growing up the little picture cards you played with had the female as the nurse, the female as the teacher and you have the male that's the doctor, the male that's the engineer. You have those pictures and that automatically associates or stereotypes doctors and engineers as male dominated careers. So as a child you're growing up already putting those two things together - that they're male industries whereas nursing and teaching is more of a female industry. Things are changing but you still look now, books you get are still a female is the nurse, a female is the teacher, you don't see a cartoon or a picture of a male nurse, or a male teacher, or a female engineer (S7).

Another said:

STEM is male dominated industry. Because we're females, we have to think about in the future what happens when we have kids, are they going to be flexible enough for us to raise a family or are we just going to end up with no kids when we're older with relatively miserable lives. I feel if 1 went into an industry dominated by males it would be harder for me to get a job as well because they have less commitments to the family than a woman does (S6).

A third participant emphasized the impact of gender stereotyping: "When 1 was a child 1 felt you could be a secretary, a nurse, a teacher, and l ended up becoming a nanny before I did this. So these are very female orientated roles and this is what I felt from my own family and friends and society is what was expected - those are careers that would be good for you since you're a woman" (S10). The fourth participant said she did try to break the mould but admitted: "I tried doing Biology but at my school it had so many males - 1 just dropped out of it. It was so dominated by males and l didn't feel comfortable to speak freely in Biology class" (S4).

Theme 7: STEM is not a safe option, was taken up by our informants. Two students commented that they just wanted to take the easy and safe option. One said "I'm a nurse but didn't really want to take on the sciences to be a doctor" (S5). Another said: "I simply did psychology in my first degree as 1 thought it would be the easy way to get a degree" (S1).

Theme 8: Lack of motivation to do STEM, was a topic of concern to many informants. Seven participants spoke of their lack of motivation to undertake a 'fancy degree':

Probably my motivation to do it wasn't that great. 1 lacked information, family and community support, knowledge, familiarity and encouragement to go into these fancy degrees. I never really got informed about the wide variety that could have been available in the STEM field - thought it meant IT stuff and really didn't like that. I needed to be more encouraged whilst at school to do something like engineering. I wasn't encouraged to pursue science at my school - in fact subject lines didn't permit it (S4).

One said simply: "I wasn't motivated" (S5). Another pointed out that: "I don't think STEM is interesting so I think I would struggle" (S8). A third participant said: "It's not something l suppose l'm passionate about and 1 believe that when you go for a job you've got to be passionate about it. STEM does wonderful things but 1 think you do need to have a passion to be able to do it" (S7). There was a slight variation in the response from S6 who said: "Maths isn't really a problem for me, l'm good at maths but l just don't find it interesting. Maybe with the science side it could be interesting but you have to know what you want to do, be pretty passionate and give up a lot of things" (S6). An even more positive view about STEM was enunciated by S10 who said:

One of our tutors was really great at explaining everything and very passionate about her field of microbiology and water cleanliness, and shared photos with us of her doing her experiments and everything. It's not something I would have ever considered but l found it really interesting and she was very enthusiastic about her field. Like l said before I think for me midwifery was very familiar. l'm very, very passionate about it which helps me (S10).

Finally one informant said that if you wanted to do STEM you need to "dream big" (S2).

Theme 9: Lack of finances to complete a STEM degree, raised concerns about the need to have finances to complete a degree in STEM: "I feel like 1 would need lots of money so l could quit my job and live in the library" (S6). Another informant said: "STEM costs money but you want to provide for your family, you want to have that house, you want to have that car and you want to be able to go on that holiday and honestly without money you really can't do that' (S7).

Theme 10: Insufficient information about STEM pathways, made it clear that early marketing of STEM courses was essential. One participant mentioned this:

I think to have more people go into that industry or to start think its interesting maybe at school age or when you're younger, in primary school even, you need to be shown more about STEM stuff-going more into depth of how to do it. Because you always hear about the nurses and the teachers and the doctors and the ambulance and the fireman and the policeman but you never really hear about the biochemist or the engineer that makes prosthetic arms or robots or all those sort of things. I think if you put it across to a young child especially about building something like a robot that would spark their interest and if you spark it then that interest can turn into a passion as they grow older which will bring them into that industry more. Whereas when 1 was a kid it was nursing and teaching (S7). 


\section{Findings and recommendations}

Authors such Green (1997), Galton \& Blachford (2000), West et al. (2010) and Tobbell et al. (2014), have all researched early educational transitions into STEM. Like us they have concluded that the successful recruitment, retention and eventual success of students into STEM degrees depends greatly on the type of pathways and support that are offered during their schooling and in their transition to university. This is especially true for young women. Such support is not only a key to individual success but also an important strategy to adopt for economic and social reasons. As we mentioned at the outset of this article, developed countries are, to some extent, faced with a STEM crisis (Morley \& Lugg, 2009; Hulme \& Wilde, 2015). It is essential to assist students early on to make an informed choice about STEM subjects if we are to ensure the sustainability of such disciplines. Yorke \& Longden (2008) surveyed first-year university students about their experiences in twenty five institutions and across nine broad discipline areas, and found that an important reason for "[...] withdrawal by some students was wrong choice of field of study" (Yorke \& Longden, 2008, p. 52). In our own case study we found that many first year female students had difficulty getting information from their school teachers, career advisers and family or friends about the right academic path to take. We established, as did other scholars, that understanding and tackling transition from pre-tertiary education into higher education was important if students were to make the right choice of subject, including the possibility of enrolling in STEM courses (Hulme $\&$ Wilde, 2015). In the focus group discussions we learned that our informants were affected in terms of subject choice by psychological factors such as low self esteem. They believed, for the most part, that even if they had the skills and abilities to undertake the study of STEM subjects, they felt nervous about doing so because they lacked encouragement during their secondary schooling.

The steps the student makes while transitioning from pre-tertiary to higher education are the beginning of a difficult educational journey (Wakeling \& Hampden-Thompson, 2013). A successful transition requires students to understand the nature of their chosen academic discipline. There appears to be a mismatch in the way that STEM subjects are presented during the students' pre-tertiary phase compared to when they begin higher education (Hulme \& Wilde, 2015, p. 15). Based on our own study we agree with the suggestion that students can have "[...] unrealistic expectations in relation to the nature and extent of autonomous learning, the teaching methods they would encounter within higher education, and levels of achievement that academics in STEM subjects often demand [...]" (Hulme \& Wilde, 2015, p. 6). Because of these unrealistic expectations students question their own ability to make a successful transition and this results in academic disengagement (Rowley \& Hartley, 2008, p. 11). Our research was preparatory in nature but indicated that more work needs to be done to develop a better understanding of student expectations of tertiary study (Johnson, 2003). We also recommend that more work be done on the importance of creating strong female role models in STEM. The above point is one that the 2014 OECD report on Fostering Equity in Higher Education emphasized.

Huhman (2016, p. 1) points out that "[...] today, women hold only $27 \%$ of all computer science jobs, and that number is not growing". The OECD report stresses that mentoring programs prior to and during the first year at university have had a beneficial effect on female student intentions to pursue a STEM degree at university and complete it (Organisation for Economic Co-operation and Development, 2014, p. 26; DuBois \& Karcher, 2011). Providers within the higher education sector need to become more involved with pre-tertiary policy and practice in terms of explaining to high school and first-year university students the nature of STEM curricula and the strategies and skills that can lead to success in undertaking those curricula. STEM educators can also assist by lobbying for resource sharing, smaller class sizes, greater visibility of female role models and a proactive approach to preparing students for transition from secondary schooling to tertiary study. Our study, and other action research initiatives, such as the study carried out by the Royal Melbourne Institute of Technology (Australian Council of Learned Academies, 2013), suggest viable ways of engendering greater diversity within STEM subjects by not only increasing the recruitment of female applicants but also by attracting more potential applicants from low SES backgrounds.

\section{References}

Australian Bureau of Statistics. (2001). Australian demographics statistics (cat. no. 3101.0). Canberra: Australian Government.

Australian Council of Learned Academies. (2013). Stem country comparisons: International comparisons of science, technology, engineering and mathematics (STEM) education: final report. Melbourne: ACOLA.

Boaler, B., \& Mckenna, T. (2011). Engaging the disengaged. New York: Cambridge University Press.

Carr, W., \& Kemmis, S. (1986). Becoming critical: education, knowledge and action research. Geelong: Deakin University Press.

Christie, M., \& Nordlund, L. (2006). The quality of assessment: who decides?. In M. Christie (Ed.), Shifting perspectives in engineering education. Gothenburg: CSELT. 
Department of Education Science and Training. (2006). Careers and transition: employability skills. Victoria.

Department of Education Science and Training. (2015). Australian maths and science partnerships programme. Victoria. Retrieved in 09 Sept 2016, from https://www.education.gov.au/australian-maths-and-science-partnerships-programme-amspp.

Dewey, J. (1916). Democracy and education: an Introduction to the Philosophy of Education. New York: Macmillan.

DuBois, D. L., \& Karcher, M. J. (2011). Handbook of youth mentoring. Washington, DC: Sage Publications.

Eisenhart, M. A., \& Finkel, E. (1998). Women's science: learning and succeeding form the margins. Philadelphia: Temple University Press.

Equal Opportunity of Women in the Workplace Agency. (2005). Annual Report 05-06 (pp. 30-35) North Sydney: EOWA.

Fielden, S. L., \& Davidson, M. J. (Eds). (2010). International research handbook on successful women entrepreneurs. Cheltenham: Edward Elgar.

Freeman, B. (2004). Women in Engineering Science and Technology: education and career challenges. New York: Engineering Science Reference.

Galton, M., \& Blachford, P. (2000). The class size debate. Is small better? Philadelphia: Open University Press.

Glover, J. (2002). Women and scientific employment: current perspectives from the UK. Scientific Studies., 15(1), 29-45.

Green, L. (1997). Music, Gender and Education. Cambridge: Cambridge University Press.

Hanson, S. L. (1996). Lost talent: women in the sciences. Philadelphia: Temple University Press.

Huhman, H. R. (2016). STEM fields and the gender gap: where are the women? New York: Forbes. Retrieved in 09 Sept 2016, from http://www.forbes.com/sites/work-inprogress/2012/06/20/stem-fields-and-the-gender-gap-where-are-the-women/\#2ead5b3b33a9

Hulme, J. A., \& Wilde, J. (2015). Tackling transition in STEM disciplines: supporting the Science, Technology, Engineering and Mathematics (STEM) student journey into higher education in England and Wales. York: Higher Education Academy.

Johnson, B. (2003). The first year at university: teaching students in Transition. New York: McGraw Hill.

Kemmis, S., \& McTaggart, R. (Eds.). (1988). The action research planner (2nd ed.). Geelong: Deakin University Press.

Lal, B., Yoon, S., \& Carlson, K. (1999). How large is the gap in salaries of male and female engineers? Virginia: National Science Foundation. Retrieved in 09 Sept 2016, from http://www.nsf.gov/sbe/srs/issuebrf/sib99352.pdf.

Lewin, K. (1946). Action research and minority problems. The Journal of Social lssues, 2(4), 34-46. http://dx.doi.org/10.1111/j.1540-4560.1946. tb02295.x.

McCullough, P. (2004). Physics Education Research Conference. Sacramento: American Institute of Physics.

McNiff, J. (2013). Action research: principles and practice (3rd ed.). Abington: Routledge.

Mezirow. (1991) Transformative dimensions of adult learning. Chichester: Wiley.

Morley, L., \& Lugg, R. (2009). Mapping Meritocracy: intersecting gender, poverty and higher educational opportunity structures. Higher Education Policy, 22(1), 37-60. http://dx.doi.org/10.1057/hep.2008.26.

National Centre for Education Statistics. (1997). Women in mathematics and science (Findings from the Condition of Education, 11, pp. 14-20, NCES 97-982). Washington, DC: U.S. Department of Education.

National Centre for Education Statistics. (2013). STEM Attrition: college students' paths into and out of STEM fields: statistical analysis report (NCES 2014-001). Washington, DC: U.S. Department of Education.

National Science Board. (2010). Higher education in science and engineering. In Science and Engineering Indicators 2010. (Chap. 2, pp. 2-41, NSB 10-01). Arlington: National Science Foundation.

National Science Foundation. (2004). Science and engineering indicators 2004 (Vol. 1, NSB 04-1). Arlington: National Science Foundation.

Organisation for Economic Co-operation and Development. (2014). Fostering equity in higher education compendium of practical case studies: promoting female participation in STEM. Paris: OECD.

Probert, B. (2005). 1 just couldn't fit it in: gender and unequal outcomes in academic careers. Gender, Work and Organization, 12(1), 50-72. http://dx.doi.org/10.1111/j.1468-0432.2005.00262.x.

Roberts, P., \& Arye, M. (2002). Counting the losses.......The Careers Review of Engineering Women: an investigation of women's retention in the Australian engineering workforce. The National Women in Engineering Committee.

Rowley, J., \& Hartley, R. (2008). Organizing knowledge. Hampshire: Ashgate Publishing.

Strachan, G., Whitehouse, G., Peetz, D., Bailey, J., \& Broadbent, K. (2008). Gender equity in universities: should we be worried? Gender and Education, 11(3), 323-342.

The House of Lords Science and Technology Committee. (2012). Behaviour change. London: The Stationery Office Limited.

Thomas, G. (2014). Closing the policy-practice gap for low-SES students in higher education: the pedagogical challenge. Higher Education Research \& Development, 33(4), 807-820. http://dx.doi.org/10.1080/07294360.2013.863846.

Tobbell, J., O’Donnell, V. L., \& Zammit, M. (2014). Exploring transition to postgraduate study: shifting identities in interaction with communities, practice and participation. British Educational Research Journal, 36(2), 261-278. http://dx.doi.org/10.1080/01411920902836360.

Wakeling, P., \& Hampden-Thompson, G. (2013). Transition to higher degrees across the UK: an analysis of national, institutional and individual differences. York: Higher Education Academy.

Wallace, N., \& Sheldon, M. (2014). Enhancing career pathways. Australia: Springer.

West, P., Sweeting, H., \& Young, P. (2010). Transitions matters: pupil's experiences of the primary-secondary transition in the West of Scotland and consequences for wellbeing and attainment. Research Papers in Education, 25(1), 21-50. http://dx.doi. org/10.1080/02671520802308677.

Whitehead, J., \& McNiff, J. (2006). Action Research: Living Theory. New York: Sage.

Yorke, A., \& Longden, M. (2008). How to Recruit and Retain Higher Education Students: A Handbook of Good Practice. New York: Routledge. 